\title{
Evaluation of Anthropometric and Biochemical Status in Children with Nutritional Deficiency
}

\author{
Man Lidia1, Pitea Ana Maria1, Chinceșan Mihaela loana¹, Man A², Mărginean Oana¹, Baghiu Maria \\ Despina $^{1}$
}

1 Pediatric Clinic I, University of Medicine and Pharmacy, Tîrgu Mureș, Romania

2 Department of Microbiology, Laboratory Medicine, University of Medicine and Pharmacy, Tîrgu Mureș, Romania

\begin{abstract}
Objective: To evaluate the anthropometric and biochemical status of children with nutritional deficiency.
Methods: We have conducted a prospective study on 226 children admitted in Pediatric Clinic I, divided into two groups: one group of 49 children with nutritional deficiency (body-mass-index <-2SD) and one control group (177 children). We have followed demographic data, anthropometric indices evaluated as standard deviations (weight, height, middle upper-arm circumference, tricipital skinfold), biochemical proteic status (Insulin-like Growth Factor 1 IGF-1, albumin, total proteins). We also followed parameters of general nutritional biochemistry. Results: The mean age for underweight children was 5.8 years, lower than in the control group. The weight of the nutritional-deficient group was significantly lower than in the control group, unlike the height $(p<0.001)$. We have also found significant differences in body-mass-index, middle upper-arm circumference and tricipital skinfold, all of them with low SDs in children with nutritional deficiency. Regarding the biochemical markers, we have found significantly higher values of transaminases $(p<0.001)$ and lower IGF-1 $(p=0.02)$ and total proteins $(p=0.013)$ in nutritional-deficient group. Most IGF-1 values were in normal range in both groups, but with a higher percent of low values in nutritional deficient children (37.5\% vs $14.2 \%, p=0.0046)$. There were no significant differences in height, albumin, cholesterol, triglyceride and glucose levels between the two groups.

Conclusions: The anthropometric measurements are the most precise methods in evaluating the nutritional status. Among the studied biochemical markers, IGF-1, total proteins and transaminases are correlated with nutritional deficiencies.
\end{abstract}

Keywords: nutritional status, anthropometry, Insulin-Like Growth Factor I, child, blood proteins

Received: 13 July 2013

\section{Introduction}

The evaluation of nutritional status can be approached by using a combination of anthropometric, clinical, biochemical data and case history in combination, and not as individual parameters, because each of them may vary in a wide range.

The evaluation of biochemical markers is a must nowadays, in order to complete the clinical diagnosis. It seems that Insulin-like Growth Factor 1 (IGF-1) and other serum proteins are related to the nutritional status. IGF-1 has an important endocrine role in the children development, by mediating the growth-hormone activity and increasing the anabolic processes. IGF-1 has an important role also in adults, its persistent low values being associated with a high mortality [1]. The secretion of IGF-1 is affected by growth hormone, IL-1 $\beta$ and TNF- $\alpha$ [2]. Due to an insufficient food intake, the metabolic disorders, including a low level of IGF-1 will lead to lower muscle gain, improper lipolysis and fat oxidation, with central body fat gain. When these changes are combined with a future high fat/carbohydrate based nutrition and lack of physical activity, obesity with short stature will occur $[3,4]$.

The morbidity and mortality of the malnourished children is high, even one year after treated for moderate acute

Correspondence to: Lidia Man

E-mail: lidia.man@gmail.com malnutrition, and lead to high cost of hospitalization by an increased length of stay and frequent readmissions [5-7]. Thereby, strategies to prevent and treat malnutrition must be implemented, by actively monitoring the hospitalized children in every possible mean: case history, clinical examination, anthropometrical measurements, and laboratory analyses, seen as a whole.

\section{Purpose}

This study aimed to evaluate the anthropometric and biochemical status in children with nutritional deficiency, focusing on IGF-1 implication both generally and between various pathologies.

\section{Materials and methods}

We have conducted a prospective study on 226 consecutively hospitalized patients admitted in Pediatric Clinic I, between November 2009 and March 2013 for several pathologies. We have divided the children in two groups: the first group with nutritional deficiency and the second as control. We considered as nutritional deficient (ND) all the children with a body mass index (BMI) under -2 standard deviations (SD), according to the WHO standards [8]. The control group consisted in children with Gaussian distribution of BMI according to Kolmogorov-Smirnov test, between -2 and $+2 \mathrm{SD}$, the members of this group being analyzed previously in another study, not related with our purpose [9]. 


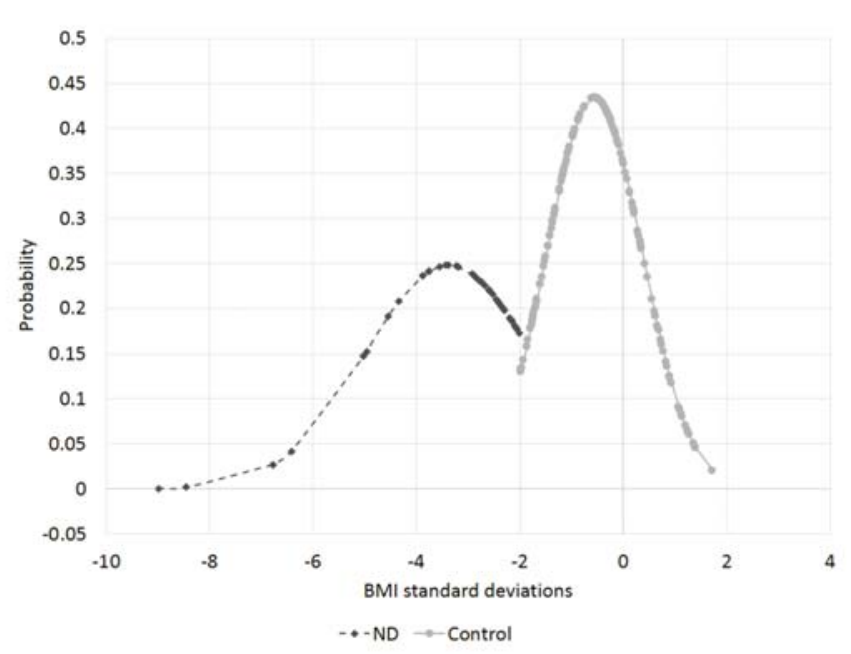

Fig. 1. Distribution of BMI SD of the two groups

We have followed aspects regarding the personal data (age, gender), anthropometric indices evaluated as standard deviations (SD for weight, height, BMI, middle upperarm circumference - MUAC which reflects the muscular mass, tricipital skinfold - TSF which reflects the fat mass) and biochemical status of several serum protein molecules (IGF-1, albumin, total proteins).

The weight was measured with an electronic scale, the height with a stadiometer/infantometer, the MUAC with a flexible meter and the TSF with a digital caliper, according to the standard procedures described by CDC [10]. The $\mathrm{SD}$ values for each anthropometric index were calculated automatically according to Switzerland Growth Chart 1989 and Netherland Growth Chart 1997, using the age, weight, height and gender as inputs in Growth Analyser v3.5 software (the last freeware version). All anthropometric measurements were performed in triplicate, and the mean value was noted.

We also followed aspects of general nutritional biochemistry (transaminases, lipids, glucose). As IGF varies with the age, we have taken in consideration this aspect when we compared IGF values to the normal reference values. The laboratory assays were performed in the Central Biochemistry Laboratory within the County Emergency Clinical Hospital Tîrgu Mureș.

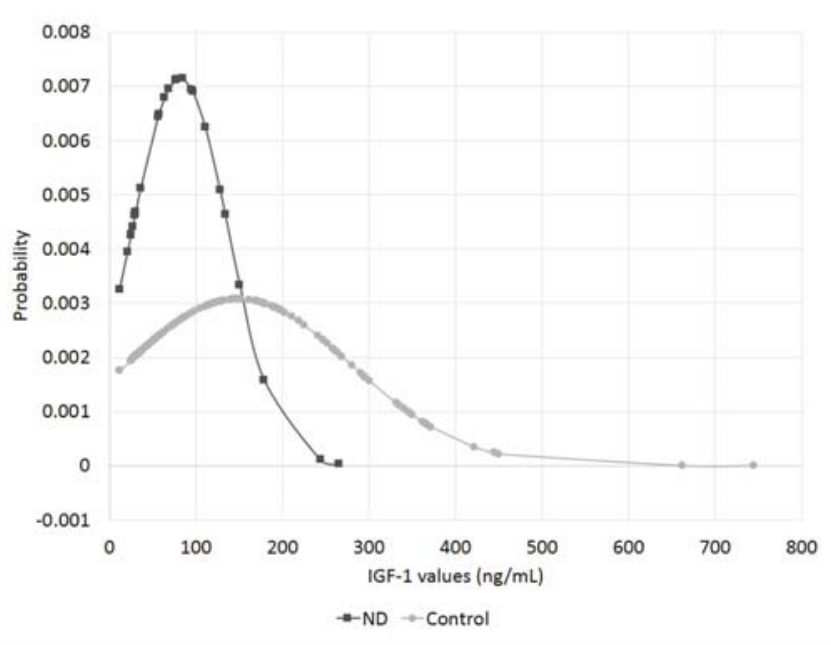

Fig. 2. Distribution of IGF-1 values of the two groups

All calculations were performed in Office spreadsheet and GraphPad InStat 3 software, using descriptive statistics, two-tailed Mann-Whitney nonparametric test or unpaired t-test and Fisher test for statistical significance interpretation. The significance level was established for $\mathrm{p}$ value under 0.05 , with a confidence interval of $95 \%$.

\section{Results}

The first group consisted in 49 children (21.7\%) with nutritional deficiency; the control group included 177 children $(78.3 \%)$.

The genders were approximately equally represented, with a higher proportion of boys $(53 \%)$. There was no difference regarding the nutritional status in boys vs girls ( $\mathrm{p}$ $=0.332$ ).

The mean age for underweight children was $5.8( \pm 4.9)$ years, lower than in the control group, which had a mean of $7.8( \pm 5.3)$ years, the difference being statistically significant $(p=0.0089)$. The median value for age was 4.2 years for the ND group and 6.5 for the control group. In both groups, the children were aged between 2 months and 18 years.

The mean weight of the children was $-2.95 \mathrm{SD}$ in the ND group (values between -0.43 and $-14.71 \mathrm{SD}$ ) and $-0.65 \mathrm{SD}$ in the control group (values between -4.2 and

Table I. Detailed anthropometric results

\begin{tabular}{|c|c|c|c|c|c|c|c|}
\hline SD of & Group & Mean & Median & Minimum & Maximum & SD & $p$ \\
\hline \multirow[t]{2}{*}{ Weight } & ND & -2.95 & -2.34 & -14.71 & -0.43 & 2.46 & $<0.0001$ \\
\hline & Control & -0.65 & -0.62 & -4.27 & 6.30 & 1.41 & \\
\hline \multirow[t]{2}{*}{ Height } & ND & -0.96 & -1 & -7.43 & 3.6 & 2.2 & 0.449 \\
\hline & Control & -0.56 & -0.62 & -4.33 & 6.50 & 1.47 & \\
\hline \multirow[t]{2}{*}{ BMI } & ND & -3.38 & -2.74 & -8.98 & -2.01 & 1.61 & $<0.0001$ \\
\hline & Control & -0.55 & -0.56 & -1.98 & 1.73 & 0.92 & \\
\hline \multirow[t]{2}{*}{ MUAC } & ND & -2.93 & -1.03 & -9.12 & 0.58 & 1.61 & $<0.0001$ \\
\hline & Control & -2.6 & -1 & -4.96 & 3.38 & 1.26 & \\
\hline \multirow[t]{2}{*}{ TSF } & ND & -2.66 & -2.4 & -8.39 & -0.05 & 1.69 & $<0.0001$ \\
\hline & & -1.06 & -1.2 & -4.1 & 2.71 & 1.15 & \\
\hline
\end{tabular}


Table II. Detailed biochemical results

\begin{tabular}{|c|c|c|c|c|c|c|c|}
\hline SD of & Group & Mean & Median & Minimum & Maximum & $\mathrm{SD}$ & $\mathrm{p}$ (medians) \\
\hline \multirow[t]{2}{*}{ IGF-1 (ng/ml) } & ND & 81.9 & 68.6 & 12 & 266 & 55.8 & 0.020 \\
\hline & Control & 149.8 & 114 & 12 & 745 & 130 & \\
\hline \multirow[t]{2}{*}{ AST (U/L) } & ND & 37.3 & 35.2 & 14 & 87.5 & 17.2 & 0.001 \\
\hline & Control & 29.4 & 27.6 & 10.4 & 97 & 13.1 & \\
\hline \multirow[t]{2}{*}{$\mathrm{ALT}(\mathrm{U} / \mathrm{L})$} & ND & 24.2 & 22 & 6.8 & 79 & 13.6 & 0.001 \\
\hline & Control & 23.7 & 14.5 & 2 & 434 & 45.9 & \\
\hline \multirow[t]{2}{*}{ Total proteins (g/dL) } & ND & 6.6 & 6.78 & 5.2 & 8.1 & 0.78 & 0.013 \\
\hline & Control & 6.98 & 7.1 & 3.7 & 9.2 & 0.86 & \\
\hline \multirow[t]{2}{*}{ Albumin (g/dL) } & ND & 3.98 & 4 & 2.5 & 4.9 & 0.61 & 0.788 \\
\hline & Control & 4.01 & 4.1 & 2.5 & 5.3 & 0.55 & \\
\hline \multirow[t]{2}{*}{ Cholesterol (mg/dL) } & ND & 150.2 & 153 & 101 & 209 & 29.8 & 0.506 \\
\hline & Control & 153.8 & 152.9 & 77 & 232 & 30.2 & \\
\hline \multirow[t]{2}{*}{ Triglyceride (mg/dL) } & ND & 106.3 & 78.1 & 33 & 271 & 68.9 & 0.162 \\
\hline & Control & 85.7 & 70 & 29 & 346 & 47.5 & \\
\hline \multirow[t]{2}{*}{ Glucose (mg/dL) } & ND & 82.8 & 81 & 55 & 128 & 13.8 & 0.510 \\
\hline & & 83.9 & 83.5 & 41 & 155 & 14.1 & \\
\hline
\end{tabular}

6.3 SD) ( $\mathrm{p}<0.001)$. The mean height was lower in the ND group ( $-0.96 \mathrm{SD}$, between -7 and $3.6 \mathrm{SD})$ compared with the control group ( $-0.57 \mathrm{SD}$, between -4.3 and 6.5$)$, but the difference was not statistically significant.

We have also found significant differences in BMI, MUAC and TSF, all of them with low SDs in ND children. The BMIs in ND children were between -8.98 and -2.01 $\mathrm{SD}$, with a mean of $-3.38 \pm 1.6$. In the control group, the BMIs were situated between -1.98 and $1.73 \mathrm{SD}$, with a mean of $-0.55 \pm 0.9 \mathrm{SD}$. The Kolmogorov-Smirnov test showed a normal distribution of BMI SDs only in the control group (Figure 1). The detailed anthropometric results for all measurements are presented in Table I.

Regarding the biochemical markers, we have found lower values for IGF-1 $(\mathrm{p}=0.02)$ in the ND group, with a mean value of $81.98 \mathrm{ng} / \mathrm{ml}$ and a median of $68.6 \mathrm{ng} / \mathrm{ml}$, whereas in the control group the mean value was $149.8 \mathrm{ng} / \mathrm{ml}$ and the median $114 \mathrm{ng} / \mathrm{ml}$. Most IGF-1 values were in normal range on both groups, but with a higher percent of low values in ND children (37.5\% vs $14.2 \%, \mathrm{p}=0.0046$ ) (Figure 2 ).

The transaminases had higher mean values in ND group ( $\mathrm{p}=0.0011$ for AST and $\mathrm{p}=0.0016$ for ALT). The total proteins mean values were lower in NG group $(p=0.013)$. There were no significant differences in the mean levels of albumin, cholesterol, glucose and triglyceride between the two groups. The detailed biochemical results are presented in Table II.

Table III. Primary pathology of the two groups

\begin{tabular}{lcccc}
\hline & \multicolumn{3}{c}{ ND } & \multicolumn{2}{c}{ Control } \\
\cline { 2 - 5 } & $\mathrm{n}$ & $\%$ & $\mathrm{n}$ & $\%$ \\
\hline Nutritional disorders & 21 & $42.9 \%$ & 33 & $18.6 \%$ \\
Digestive & 10 & $20.4 \%$ & 36 & $20.3 \%$ \\
Oncology & 5 & $10.2 \%$ & 29 & $16.4 \%$ \\
Hematology & 3 & $6.1 \%$ & 47 & $26.6 \%$ \\
Pulmonary & 2 & $4.1 \%$ & 20 & $11.3 \%$ \\
Others & 8 & $16.3 \%$ & 12 & $6.8 \%$ \\
\hline
\end{tabular}

In the ND group, most children have been hospitalized because of nutritional and digestive disorders. In control group the most frequent pathologies were hematological and digestive disorders (Table III). The IGF-1 values were significantly lower in the ND children with digestive, pulmonary and hematological disorders. In other pathologies, though the IGF-1 values were lower in ND children, there are no statistical differences with the control group (Table IV).

\section{Discussions}

The nutritional deficiencies are a real problem throughout the world, especially in developing countries and must be properly evaluated. The assessment of nutritional status can be evaluated by many anthropometrical measurements (weight, height, body mass index, skinfolds, upper arm, waist or head circumference, upper leg or arm length, handgrip strength, etc.). Fortunately, the methods used for this assessment are easy to perform with only a few equipment and maybe the most important, they do not cost much. There are studies that confirm the reliability of these measurements $[11,12]$, but there are also studies that describes them as imprecise and unreliable (training of the personnel, technical errors, associated pathology, etc.) $[13,14]$.

The BMI is the best screening tool for evaluation of body fat in children and adolescents, but not in other situations, as evaluating the cardio-metabolic risk $[15,16]$. It seems that are some reliability issues with MUAC, waist circumference and TSF that will limit their utilization in longitudinal studies. Some methods are quick to perform and can be successfully used in emergency cases or remote sites [11]. It seems that some indices, as the ideal weight for height, sex, and age, cannot identify the children with values under $80 \%$ weight for age [17].

In order to compare the actual values of anthropometric measurements with the standards for age and gender, we choose to operate with standard deviations for each measurement, as they are easier to follow. We used the BMI 
Table IV. IGF-1 value details within different pathologies of the two groups

\begin{tabular}{|c|c|c|c|c|c|c|c|}
\hline \multirow[t]{2}{*}{ Pathology } & \multicolumn{3}{|c|}{ IGF-1 in ND } & \multicolumn{3}{|c|}{ IGF-1 in control } & \multirow[t]{2}{*}{$\mathrm{p}$ (medians) } \\
\hline & Mean & Median & SD & Mean & Median & SD & \\
\hline Nutritional disorders & 65 & 63 & 46.8 & 72.4 & 49 & 77.9 & 0.7875 \\
\hline Digestive & 74.4 & 27.1 & 96.7 & 152.8 & 110 & 121.9 & 0.0438 \\
\hline Hematology & 24.2 & 24.2 & 17.2 & 174.5 & 146 & 138.2 & 0.0391 \\
\hline Pulmonary & 16.5 & 16.5 & 6.3 & 183.9 & 132 & 134.3 & 0.0095 \\
\hline Oncology & 81.5 & 77.6 & 50.9 & 101.8 & 38.5 & 142.8 & 0.6332 \\
\hline Others & 90.6 & 12 & 115 & 109.5 & 76.8 & 75.8 & 0.3097 \\
\hline
\end{tabular}

as criterion for differentiating the two nutritional status groups: with nutritional deficiency (BMI $<-2 \mathrm{SD}$ ) and normal (BMI $>-2 \mathrm{SD})$ as control. It was the best choice, all the other methods (MUAC, TSF) being consistent with the BMI, in all cases with significant difference of median values between the two groups.

The children hospitalized in hematology /oncology department within Pediatric Clinic I who were included in our study were previously analyzed from another point of view.

In our study, the genders were approximately equally represented, with a slightly higher proportion of boys. We did not found a difference between genders, regarding the nutritional disorders, though other studies report a difference in favor of boys [18-20]. According to the mean age, most nutritional-deficient were preschool children. The mean age for underweight children was significantly lower than in control, where most children were of school age.

Biochemical evaluation may be the most objective and quantitative. The evaluation of some biochemical markers can be useful tools for appreciating the nutritional status, but they must be evaluated as a whole, because the associated inflammation may influence the protein metabolism, including the IGF-1 levels [21]. Nevertheless, in our study, the IGF-1 values were significantly lower in the ND children, although they presented digestive, pulmonary and hematological disorders. Many studies support the connection between the immune system, inflammatory or malign processes and serological markers including IGF-1 $[9,22,23]$. Other studies underlines the difficulties in concluding whether IGF-1 have pro- or anti-inflammatory effects [24]. Nutrition is one of the main regulators of circulating IGF-1, its serum levels being lowered by energy and/or protein deprivation and it is correlated with the economic status $[25,26]$; the nutritional supplementation results in increasing the levels of IGF-1 [27]. In our study we have found significantly lower values and a higher percent of low values (under the detection limit) for IGF-1 in nutritional-deficient children compared to control.

The transaminases present elevated levels in malnourished patients, both children and adults [28-30]. Our results are consistent, as the transaminases, both AST and ALT, had higher values in the nutritional-deficient children.

Serum albumin is not a good marker of nutritional disorders, as its concentration is affected by many factors not related with the nutrition, nor in children or elderly $[31,32]$. Our results are consistent with this, no significant difference being found between the two groups.

The stunted children have lower serum triglyceride concentrations than non-stunted ones [33]. We did not found any significant differences in cholesterol and triglyceride levels between the nutritional-deficient and control groups.

Severe malnutrition is associated with improper glucose absorption and a low insulin response. Even a mild malnutrition decreases the intestinal intake of carbohydrates $[34,35]$. Yet, the mean glucose levels in our groups did not differ, in concordance with the reports of other studies [36].

\section{Conclusions}

According to our study, the anthropometric measurements are the most precise methods in evaluating the nutritional status; BMI is the most appropriate method for evaluation of nutritional disorders, but other methods as MUAC or TSF can be also successfully used. Among the studied biochemical markers, IGF-1, total proteins and transaminases are correlated with deficiencies in nutritional status. Other serum biochemical markers, even other proteins or lipids that are directly related to the nutrition habits, cannot be used as indicators of nutritional status. The IGF-1 values are significantly lower in the nutrition-deficient children with digestive, pulmonary and hematological disorders. Strategies to prevent and treat malnutrition must be implemented, by actively monitoring the hospitalized children by all possible means: historical, clinical, anthropometrical, and completed with specific laboratory results.

\section{Acknowledgement}

This study was conducted within the POSDRU/CPP107/ DMI1.5/S/80641 project.

\section{References}

1. Friedrich N, Schneider HJ, Haring R, et al. Improved prediction of allcause mortality by a combination of serum total testosterone and insulinlike growth factor I in adult men. Steroids. 2012;77(1-2):52-8.

2. Gude MF, Frystyk J, Flyvbjerg A, et al. The production and regulation of IGF and IGFBPs in human adipose tissue cultures. Growth Horm IGF Res Off J Growth Horm Res Soc Int IGF Res Soc. 2012;22(6):200-5.

3. Hoffman DJ, Sawaya AL, Verreschi I, Tucker KL, Roberts SB. Why are nutritionally stunted children at increased risk of obesity? Studies of metabolic rate and fat oxidation in shantytown children from São Paulo, Brazil. Am J Clin Nutr. 2000;72(3):702-7. 
4. Sawaya AL, Martins PA, Grillo LP, Florencio TT. Long-term Effects of Early Malnutrition on Body Weight Regulation. Nutr Rev. 2004;62:S127-S133.

5. Agarwal E, Ferguson M, Banks M, et al. Malnutrition and poor food intake are associated with prolonged hospital stay, frequent readmissions, and greater in-hospital mortality: Results from the Nutrition Care Day Survey 2010. Clin Nutr Edinb Scotl. Epub 2012 Dec 5.

6. Lim SL, Ong KCB, Chan YH, et al. Malnutrition and its impact on cost of hospitalization, length of stay, readmission and 3-year mortality. Clin Nutr Edinb Scotl. 2012;31(3):345-50.

7. Chang CY, Trehan I, Wang RJ, et al. Children successfully treated for moderate acute malnutrition remain at risk for malnutrition and death in the subsequent year after recovery. J Nutr. 2013;143(2):215-20.

8. WHO | WHO Child Growth Standards: Methods and development [Internet]. WHO. [cited 2013 Jun 9]. Available from: http://www.who.int/ childgrowth/standards/technical_report/en/index.html

9. Mihaela loana C, Maria Despina B, Alina G, Oana M. Compoziția corporală la copiii cu boală malignă. Rev Rom Pediatr. 2012;LXI(1):42-9.

10. BodyMeasures 09.pdf [Internet]. [cited 2013 Jun 7]. Available from: http:// www.cdc.gov/nchs/data/nhanes/nhanes_09_10/BodyMeasures_09.pdf

11. Sicotte M, Ledoux M, Zunzunegui M-V, Aboubacrine SA, Nguyen V-K. Reliability of anthropometric measures in a longitudinal cohort of patients initiating ART in West Africa. BMC Med Res Methodol. 2010 22;10(1):102.

12. Crespi CM, Alfonso VH, Whaley SE, Wang MC. Validity of child anthropometric measurements in the Special Supplemental Nutrition Program for Women, Infants, and Children. Pediatr Res. 2012;71(3):286-92.

13. Ulijaszek SJ, Kerr DA. Anthropometric measurement error and the assessment of nutritional status. Br J Nutr. 1999;82(3):165-77.

14. Stomfai S, Ahrens W, Bammann K, et al. Intra- and inter-observer reliability in anthropometric measurements in children. Int $\mathrm{J}$ Obes. 2011;35(S1):S45-S51.

15. Mei Z, Grummer-Strawn LM, Pietrobelli A, et al. Validity of body mass index compared with other body-composition screening indexes for the assessment of body fatness in children and adolescents. Am J Clin Nutr. 2002;75(6):978-85.

16. Ashwell M, Gunn P, Gibson S. Waist-to-height ratio is a better screening tool than waist circumference and BMl for adult cardiometabolic risk factors: systematic review and meta-analysis. Obes Rev. 2012;13(3):27586.

17. Bertoli S, Cardinali S, Veggiotti $P$, et al. Evaluation of nutritional status in children with refractory epilepsy. Nutr J. 2006;5(1):14.

18. Olack B, Burke H, Cosmas L, et al. Nutritional Status of Under-five Children Living in an Informal Urban Settlement in Nairobi, Kenya. J Health Popul Nutr. 2011;29(4):357-63.

19. Wamani H, Astrom AN, Peterson S, Tumwine JK, Tylleskar T. Boys are more stunted than girls in Sub-Saharan Africa: a meta-analysis of 16 demographic and health surveys. BMC Pediatr. 2007;7:17.

20. Kurz KM. Adolescent nutritional status in developing countries. Proc Nutr Soc. 1996;55(1B):321-31.
21. Young VR, Marchini JS, Cortiella J. Assessment of protein nutritional status. J Nutr. 1990;120(S11):1496-502.

22. Pass C, MacRae VE, Ahmed SF, Farquharson C. Inflammatory cytokines and the GH/IGF-I axis: novel actions on bone growth. Cell Biochem Funct. 2009;27(3):119-27.

23. Gupta N, Lustig RH, Kohn MA, McCracken M, Vittinghoff E. Sex differences in statural growth impairment in Crohn's disease: role of IGF-1. Inflamm Bowel Dis. 2011;17(11):2318-25.

24. Andreassen M, Frystyk J, Faber J, Kristensen LØ. GH activity and markers of inflammation: a crossover study in healthy volunteers treated with $\mathrm{GH}$ and a GH receptor antagonist. Eur J Endocrinol. 2012;166(5):811-9.

25. Thissen JP, Ketelslegers JM, Underwood LE. Nutritional regulation of the insulin-like growth factors. Endocr Rev. 1994;15(1):80-101.

26. Livingstone C. The Insulin-Like Growth Factor System and Nutritional Assessment. Scientifica [Internet]. 2012 Jul 29 [cited 2013 Jun 8];2012. Available from: http://www.hindawi.com/journals/ scientifica/2012/768731/abs/

27. Walker WA, Watkins JB. Nutrition in Pediatrics: Basic Science and Clinical Applications. PMPH-USA; 2003. p. 1128.

28. Hanachi M, Melchior JC, Crenn P. Hypertransaminasemia in severely malnourished adult anorexia nervosa patients: Risk factors and evolution under enteral nutrition. Clin Nutr. 2013;32(3):391-5.

29. Chowdhury MSI, Rahman AZ, Haque M, Nahar N, Taher A. Serum Aspartate Aminotransferase (AST) and Alanine Aminotransferase (ALT) Levels in Different Grades of Protein Energy Malnutrition. J Bangladesh Soc Physiol. 2007;2(0):17-9.

30. Nwosu BU, Stavre ZG, Maranda L, Cullen K, Lee MM. Hepatic dysfunction is associated with vitamin $D$ deficiency and poor glycemic control in diabetes mellitus. J Pediatr Endocrinol Metab JPEM. 2012;25(1-2):181-6.

31. Bouillanne $O$, Hay $P$, Liabaud $B$, et al. Evidence that albumin is not a suitable marker of body composition-related nutritional status in elderly patients. Nutrition. 2011;27(2):165-9.

32. Lark RK, Williams CL, Stadler D, et al. Serum prealbumin and albumin concentrations do not reflect nutritional state in children with cerebral palsy. J Pediatr. 2005;147(5):695-7.

33. Bennett F, Walker S, Gaskin P, Powell C. Fasting levels of serum glucose, cholesterol and triglyceride at age eleven to twelve years in stunted and non-stunted Jamaican children. Acta Pædiatrica. 2002;91(9):903-8.

34. Bandsma RHJ, Spoelstra MN, Mari A, et al. Impaired Glucose Absorption in Children with Severe Malnutrition. J Pediatr. 2011;158(2):282-287.e1.

35. Das BK, Ramesh J, Agarwal JK, Mishra OP, Bhatt RP. Blood sugar and serum insulin response in protein-energy malnutrition. J Trop Pediatr. 1998;44(3):139-41.

36. Mishra SK, Bastola SP, Jha B. Biochemical nutritional indicators in children with protein energy malnutrition attending Kanti Children Hospital, Kathmandu, Nepal. Kathmandu Univ Med J KUMJ. 2009;7(26):129-34. 